\title{
Amiodarone pneumonitis: three further cases with a review of published reports
}

\author{
JI DARMANATA, N van ZANDWIJK, DR DÜREN, EA van ROYEN, WJ MOOI, TA PLOMP, \\ HM JANSEN, D DURRER \\ From the Departments of Cardiology and Clinical Physiology, Pulmonary Diseases, Nuclear Medicine, and \\ Pathology, University Hospital, Wilhelmina Gasthuis, Amsterdam, and the Centre for Human Toxicology, \\ University of Utrecht, The Netherlands
}

ABSTRACT Three further patients are presented who developed evidence of a parenchymal pulmonary disturbance in the course of treatment with amiodarone. In one case the progress of the condition was rapid and ended fatally. Histological examination of the lungs showed evidence of diffuse alveolar damage. The concentration of amiodarone was from four to seven times higher in the lungs than in other organs studied. The concentration of the metabolite desethylamiodarone in the lungs was even higher in relation to other organs studied. The remaining two patients showed a more insidious onset and improvement after withdrawal of amiodarone and treatment with corticosteroids. Gallium 67 scintigraphy appeared to be a sensitive indicator of this adverse effect. Review of published reports revealed 35 cases of amiodarone pneumonitis, including the cases reported in this study. In 11 instances the dose of amiodarone was $400 \mathrm{mg}$ or less. The onset was either insidious or rapidly progressive. Exertional dyspnoea was always present and a nonproductive cough, hypoxaemia, a raised erythrocyte sedimentation rate and diminished carbon monoxide diffusing capacity (transfer factor) were usually noted. Chest radiographs showed either a reticular pattern or diffuse patchy alveolar infiltrates. Discontinuation of amiodarone and an institution of corticosteroid treatment was usually followed by improvement or resolution.

Amiodarone hydrochloride, a benzofuran derivative, was first introduced in Europe in 1967 for the treatment of angina pectoris. ${ }^{1}$ Later it was found to possess unique antiarrhythmic properties, ${ }^{2}$ particularly in association with the Wolff-Parkinson-White syndrome. ${ }^{34}$ Although corneal microdeposits, bluish skin discoloration, photosensitisation, transient increases in liver enzymes, and altered thyroid function became recognised in the $1970 \mathrm{~s},{ }^{5-8}$ attention has been only recently drawn to the association of pulmonary infiltrates with amiodarone treatment. ${ }^{9-24}$

In the two years since we reported our first patient $^{18}$ we have seen three further cases of amiodarone pneumonitis. The present report describes these three patients and reviews the published reports.

Address for reprint requests: Dr JI Darmanata, Department of Cardiology (Room $C_{2}-432$ ), Academic Medical Centre, Meibergreef 9,1105 AZ Amsterdam, The Netherlands.

Accepted 17 October 1983

\section{Case reports}

PATIENT 1

A 68 year old man received amiodarone treatment for refractory ventricular tachycardia appearing two weeks after acute myocardial infarction. A loading dose of $600 \mathrm{mg}$ was given on the first day followed by $200 \mathrm{mg}$ daily five days a week. Three weeks after starting treatment he experienced increasing dyspnoea on exertion and developed a non-productive cough. Serial chest radiographs showed the rapid development of bilateral alveolar infiltrates and a right pleural effusion (fig 1). Seven weeks after starting treatment he was transferred to our hospital. On examination we found a dyspnoeic elderly man with a normal temperature. Crackles were audible at both bases. Radionuclide angiography showed a dilated and poorly contracting left ventricle. The erythrocyte sedimentation rate was $50 \mathrm{~mm}$ in one hour. The leucocyte count was $6.1 \times 10^{9} / 1$ with $1 \%$ eosinophils. Microbiological investigation and a test for antinuclear antibody were negative. Immuno- 


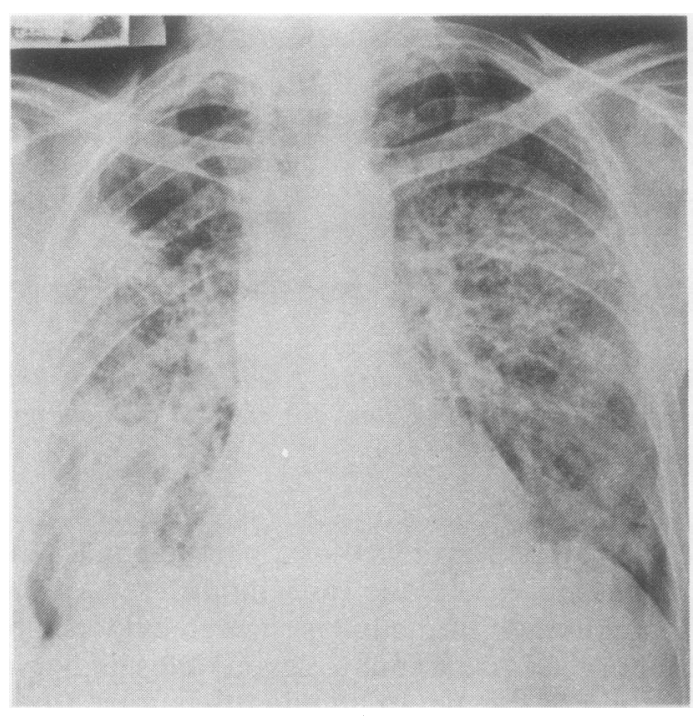

Fig 1 Radiographic changes in a patient with amiodarone induced pulmonary abnormality: patient 1 (seven weeks after amiodarone was given)-diffuse bilateral alveolar infiltrates and right pleural effusion.

globulin concentrations and complement profile were normal. Arterial blood gases during the breathing of room air showed hypoxaemia ( $\mathrm{pH} \mathrm{7.47,}$ $\mathrm{PaCO}_{2} 28 \mathrm{~mm} \mathrm{Hg}(3.7 \mathrm{kPa}), \mathrm{PaO}_{2} 70 \mathrm{~mm} \mathrm{Hg}(9.3$ $\mathrm{kPa})$ ). Despite withdrawal of amoidarone and initiation of treatment with diuretics and prednisolone, his condition rapidly deteriorated. He died two weeks after cessation of amiodarone treatment. Histological examination of lung tissue obtained at necropsy showed various stages of diffuse alveolar damage, with hyperplasia of type II pneumocytes, hyaline membrane formation, organisation of alveolar exudate, interstitial mononuclear inflammation, and fibrosis (fig 2). Tissue concentrations of amiodarone and its metabolite desethylamiodarone were determined in several organs ${ }^{25}$ (table 1). The amiodarone concentration in the lung tissue exceeded that of the heart and kidney by a factor of almost 10. Measurements of desethylamiodarone showed that the lungs had even higher concentrations in relation to other organs.

\section{PATIENT 2}

In 1981 a 55 year old man underwent coronary artery surgery for intractable angina pectoris. Two grafts were implanted on the left coronary artery. The following year he suffered an acute inferior myocardial infarction. Amiodarone $200 \mathrm{mg}$ daily was prescribed for mild angina pectoris. The dose was later increased to $600 \mathrm{mg}$ because of persistent angina. After one month of treatment with this dos-
Table 1 Postmortem tissue concentrations (means with standard deviations in parentheses) of amiodarone and desethylamiodarone in patient 1

\begin{tabular}{|c|c|c|}
\hline Tissue & $\begin{array}{l}\text { Amiodarone } \\
\text { concentration } \\
(\mu g / g)\end{array}$ & $\begin{array}{l}\text { Desethylamiodarone } \\
\text { concentration } \\
(\mu \mathrm{g} / \mathrm{g})\end{array}$ \\
\hline $\begin{array}{l}\text { Lung } \\
\text { Liver } \\
\text { Kidney } \\
\text { Heart } \\
\text { Thyroid gland }\end{array}$ & $\begin{array}{l}28(7) \\
7(1) \\
3(0 \cdot 3) \\
4(1) \\
3(1)\end{array}$ & $\begin{array}{c}238(59) \\
64(6) \\
19(2) \\
19(1) \\
13(1)\end{array}$ \\
\hline
\end{tabular}

age he developed increasing exertional dyspnoeaç and a non-productive cough with a normal tempera- ture. The patient was admitted to hospital ander amiodarone treatment was stopped after a total of nine weeks of treatment. On examination he was ${ }^{-}$ afebrile and crackles were audible at the left base. $\vec{c}$ The chest radiograph showed an area of "ground" glass" shadowing in the right lower lobe. The erythrocyte sedimentation rate was $83 \mathrm{~mm}$ in one hour and the leucocyte count was $10.2 \times 10^{9} / 1$ with $\vec{\bullet}$ 7\% eosinophils. Microbiological investigation and immunological tests gave negative results. The arterial blood gases during the breathing of room air hado a pH of $7 \cdot 38$, a $\mathrm{PaCO}_{2}$ of $36 \mathrm{~mm} \mathrm{Hg}(4 \cdot 8 \mathrm{kPa})$, and as $\mathrm{Po}_{2}$ of $65 \mathrm{~mm} \mathrm{Hg}(8.6 \mathrm{kPa})$. Pulmonary function tests showed that lung volumes were within normalo limits. Carbon monoxide diffusing capacity was $40 \% \Omega$ of the predicted value. Gallium 67 scintigraphy $\overrightarrow{\overrightarrow{0}}$ showed intense diffuse uptake in both lungs (fig 3)? In the three weeks that followed, dyspnoea persisted although the changes in the chest radiograph virtu ally resolved. Diffusing capacity decreased further to $27 \%$ of predicted normal and arterial $\mathrm{Po}_{2}$ to 50 ? $\mathrm{mm} \mathrm{Hg}(6.7 \mathrm{kPa})$. His condition improved dramati-x cally after starting treatment with prednisolone 405 $\mathrm{mg}$ daily (fig 4A). Although pulmonary diffusing capacity did not reach normal values, the chese radiograph and gallium 67 scintigraphy appearances returned to normal within three weeks. After two months the dose of prednisolone was lowered to $30 \mathrm{D}$ mg daily; but dyspnoea recurred and again pathological accumulation of gallium 67 was found $\mathbb{N}$ although the chest radiograph remained clear.

\section{PATIENT 3}

A 69 year old man was treated with amiodarone 300 mg daily because of angina pectoris. After tw $\infty$ months of treatment he experienced mild exertiona贷 dyspnoea. Pulmonary function tests gave norma ${ }^{3}$ results. A year later the chest radiograph appeared normal. After two years of treatment he was admit $\frac{\text { Oे }}{\mathbb{D}}$ ted to hospital with considerable exertional dyspnoea, non-productive cough, transient fever $\stackrel{\mathbb{Q}}{\varrho}$ abdominal discomfort, and weight loss. On examina? 

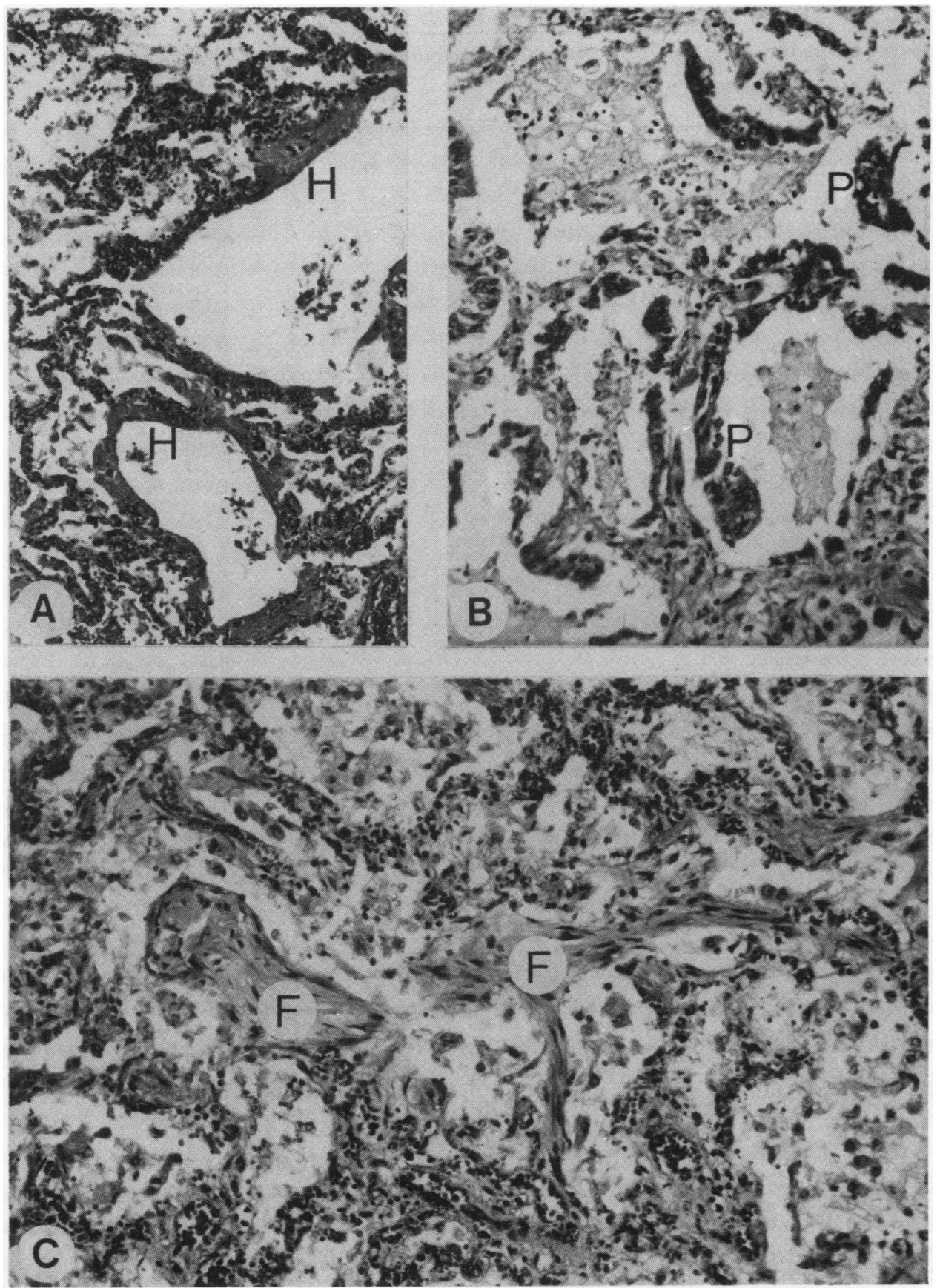

Fig 2 Histological appearances of lung tissue obtained at necropsy from patient 1 showing diffuse alveolar damage in both early and later stages: $(a)$ and $(b)$ the early stage showing interstitial and intraalveolar oedema, formation of hyaline membrane $(H)$, and hyperplasia of type II pneumocytes $(P)$; (c) later stage showing organisation of exudate, with the formation of loose fibrous tissue $(F)$ and interstitial inflammation and fibrosis. (Haematoxylin and eosin; (a) $\times 90 ;(b)$ and $(c) \times 140$.) 
Table 2 Summary of new and previously reported patients with amiodarone pneumonitis

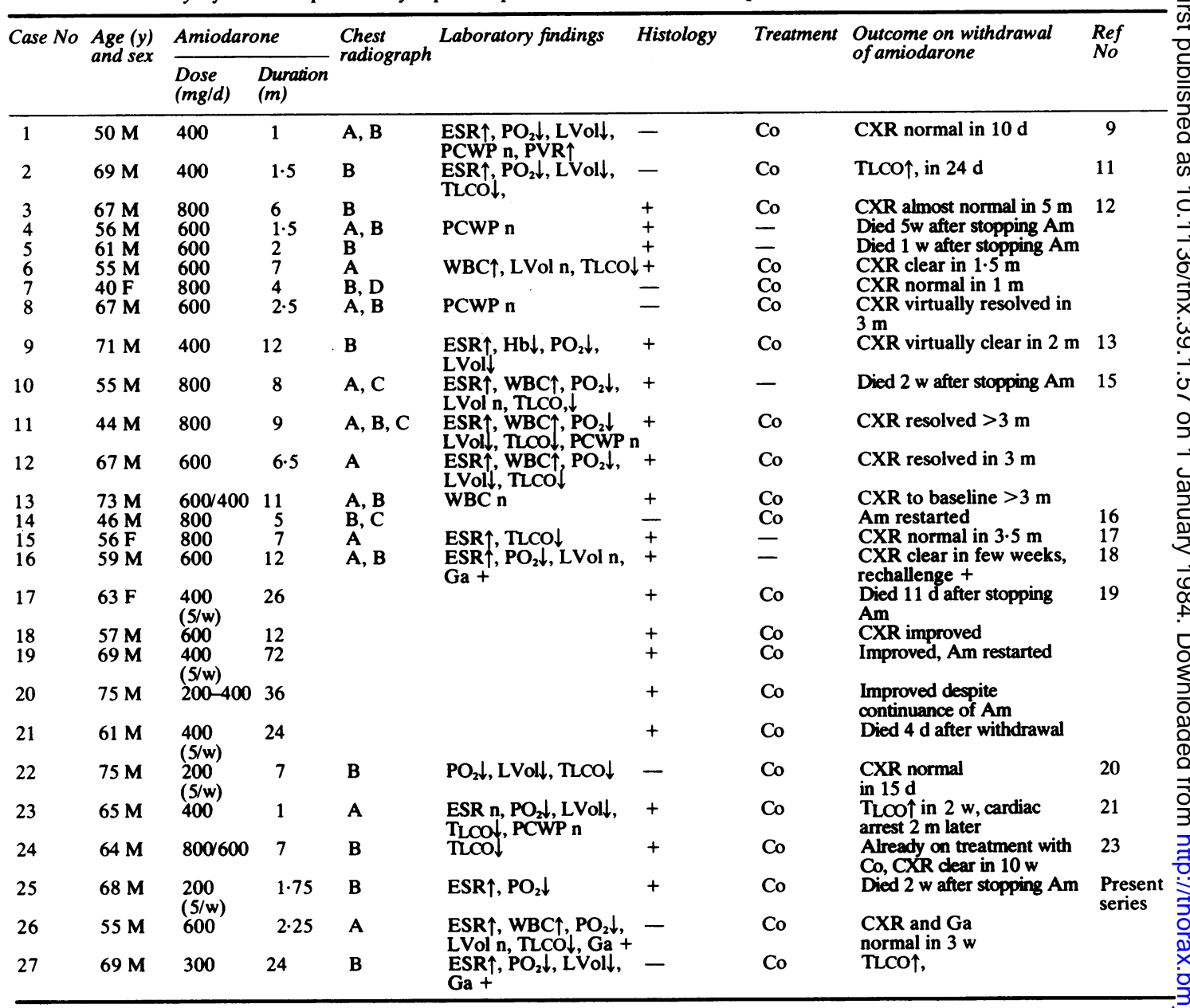

Not included in the list as no details were available: Heger et al ${ }^{10}$ reported three cases, two of them died. Two patients including one who died, were discussed by Sobol and Rakita. ${ }^{22}$ Waxman et al ${ }^{14}$ reported five patients; 4 of them were reported in detail by Marchlinski $e t$ al ${ }^{15}$ and Gefter $e t a l,{ }^{22}$ and one died. Fogoros et $a^{24}$ reported six patients with amiodarone dose of $600-800 \mathrm{mg} / \mathrm{d}$ for 3-14 months; three of them died.

A-diffuse interstitial pattern; Am-amiodarone; B-intraalveolar infiltrates; C-pleural thickening; Co-corticosteroids; CXR-chest $\mathrm{O}$ radiograph; D-pleural effusion; +-microscopic examination done; ESR-erythrocyte sedimentation rate, in one hour; Ga-Gallium 67 I scintigraphy; $\mathrm{Hb}$-haemoglobin; LVol-lung volumes, TLC and/or VC; $n$-normal; PCWP_pulmonary capillary wedge pressure; $\mathrm{Po}_{2}$-arterial oxygen pressure; $\mathrm{PVR}$ - pulmonary vascular resistance; TLCO-carbon monoxide diffusing capacity; WBC-white blood cell count.

tion he was afebrile but coarse crackles were audible at the right base. The chest radiograph showed an infiltrative pattern in the right lower lobe. Gallium 67 scintigraphy showed increased uptake in the corresponding area. Extensive investigation of possible microbiological and immunological causes yielded negative results. The erythrocyte sedimentation rate was $81 \mathrm{~mm}$ in one hour and the serum liver enzyme activities were increased. The arterial blood gases during the breathing of room air showed a $\mathrm{pH}$ of
7.39, a $\mathrm{PaCO}_{2}$ of $36 \mathrm{~mm}: \mathrm{Hg}(4 \cdot 8 \mathrm{kPa})$, and $\mathrm{a} \mathrm{PaO}_{2}$ of $72 \mathrm{~mm} \mathrm{Hg}(9.6 \mathrm{kPa})$. The vital capacity was slightly?

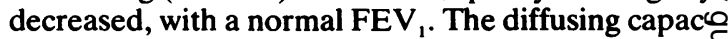
ity was $34 \%$ of the predicted value. Amiodaronee was stopped and pulmonary function tests were repeated at intervals. The lung volumes did not change appreciably and the diffusing capacity showed a slight initial increase. Treatment with? prednisolone, $40 \mathrm{mg}$ a day, was followed by furthe increase in diffusing capacity (fig 4B). 


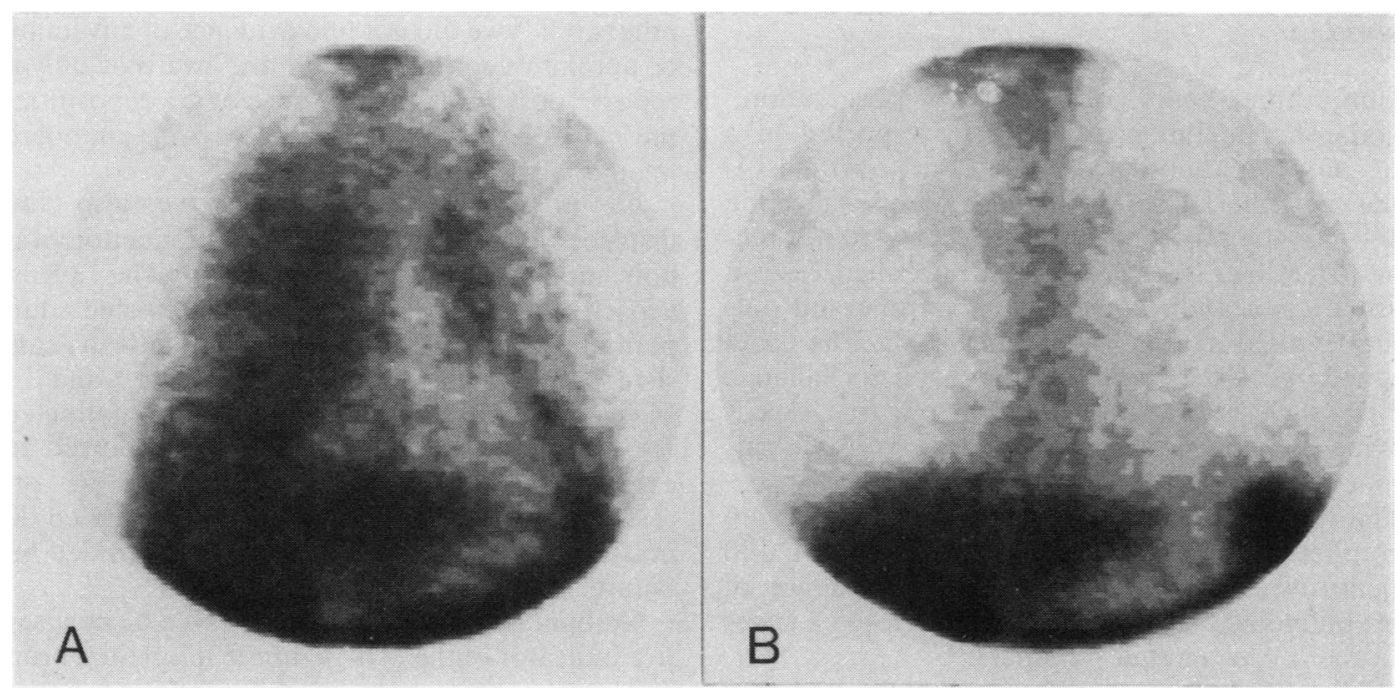

Fig 3 Gallium 67 scintigraphy from patient 2: (a) increased gallium 67 activity in both lungs one week after withdrawal of amiodarone; (b) normal appearances three weeks after starting treatment with prednisolone.

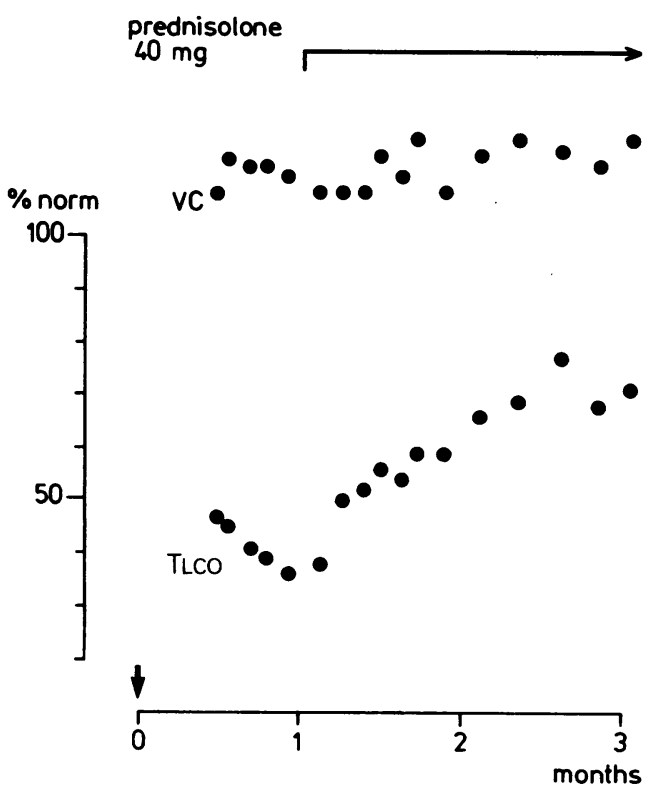

potient 2

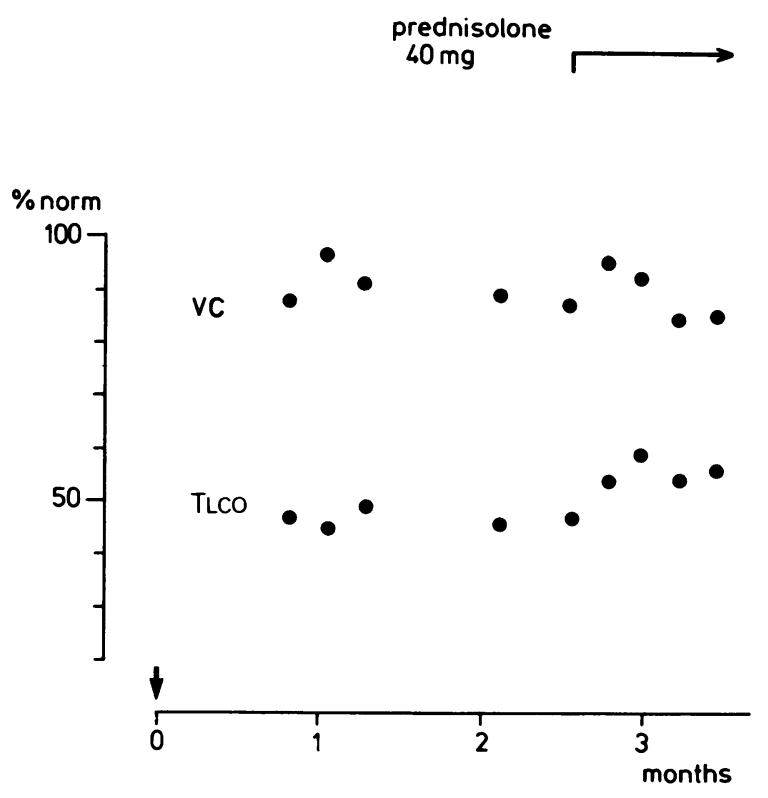

patient 3

Fig 4 Vital capacity (VC) and carbon monoxide transfer ( $T_{\mathrm{LCO}}$ ) after discontinuation of amiodarone ( $\left.\downarrow\right)$ before and during treatment with corticosteroid in two patients. Values are expressed as percentages of predicted normal values. 


\section{Discussion}

Within three years of the first observation, ${ }^{9}$ amiodarone pneumonitis has been reported in a total of 35 patients (including our own). It is remarkable that, despite its large scale use since the late 1960 s the pulmonary side effects were not recognised earlier. In the very first published cases a possible association between amiodarone and pulmonary disease was only suggested. The data accumulated since then, however, and rechallenge testing, such as that performed in our first case, ${ }^{18}$ provide convincing evidence of drug induced pulmonary changes.

The four patients observed in our hospital were encountered in a population of more than 300 patients treated with the drug. The incidence of overt pulmonary side effects may therefore be lower than the $6 \%$ estimated by others. ${ }^{15} 24$

Of the 35 patients reported, 11 have died as a result of this complication (table 2). Detailed clinical data were available for 27 patients and histopathological confirmation for 19. Most of them (21 patients) received $600-800 \mathrm{mg}$ of amiodarone daily. Marchlinski et al $^{15}$ found no instances of pulmonary adverse effects in patients maintained on $400 \mathrm{mg}$ or less of amiodarone a day. Another report ${ }^{17}$ described a case in which pulmonary complications developed only when the dose was increased to 800 $\mathrm{mg}$, a daily dose of $200 \mathrm{mg}$ having been well tolerated for the previous five years. In 11 cases (including those reported here) pulmonary adverse effects have developed in patients treated with 400 $\mathrm{mg}$ or less of amiodarone daily. ${ }^{9111319}$

All patients experienced some increase in exertional dyspnoea and in some patients this was severe. Non-productive cough and weight loss were the next most prominent symptoms. Transient fever was frequent, while pleuritic chest pain was seldom present.

At physical examination the auscultatory findings were variable. Decreased breath sounds and fine or coarse crackles were frequently noted at the lung bases and sometimes a pleural friction rub was found. The initial radiological changes were almost indistinguishable from those associated with pulmonary venous congestion. Later a diffuse interstitial pattern or patchy alveolar infiltrates were found, while pleural thickening or pleural effusion were less frequent. In our earlier report ${ }^{18}$ the pulmonary lesions became more extensive on continuation of amiodarone and showed peculiar migratory characteristics.

The ESR was generally raised and the leucocyte count was sometimes increased. Blood eosinophilia was encountered in a small proportion of cases. Like others, ${ }^{11} 1315$ we did not find evidence of any immune or autoimmune process. We are aware of only one report ${ }^{17}$ describing the presence of $\mathrm{C} 3$ depositions in the alveolar septa of a case of amiodarone pneumonitis.

As in other cases, ${ }^{11} 12151723$ we also found disturbed blood gas tensions and a reduction of carbon monoxide diffusing capacity. The diffusing capacity appeared to be most affected during periods of active, untreated pneumonitis, as can be seen from serial estimations in patients 2 and 3 (fig 4). Lung volumes seemed to be largely unaffected in two of our patients while the third showed indications of a restrictive defect, as in other cases. $^{911} 13152021$ Spirometry may be of limited diagnostic value as it can be affected by left sided heart failure.

Gallium 67 scintigraphy ${ }^{18}$ appeared to be a sensitive indicator of the activity of the interstitial process and was a great help in differentiating between pneumonitis and left sided heart failure. In our previous case ${ }^{18}$ and in patient 2 , it showed increased uptake in the lungs before any changes could be detected on the chest radiograph. Similar observations have been made with pulmonary sarcoidosis. ${ }^{26}$

The microscopic changes seen in transbronchial lung biopsy ${ }^{18}$ and necropsy specimens in our patients were consistent with the pathological findings of others. ${ }^{101215}$ These changes were non-specific and correspond well with the description given by Katzenstein and Askin $^{27}$ of diffuse alveolar damagethat is, a limited reaction of the lung to injury. The high concentration of amiodarone and its metabolite desethylamiodarone found in the lung tissue, as in patient 1 , may indicate a toxic origin of the pulmonary damage observed. It seems unlikely that amiodarone or its metabolite produced toxic effects in the lung, since one of us ${ }^{25}$ found high concentrations in a single postmortem examination of a patient dying without symptoms or overt pulmonary $ᄋ$ changes. There is experimental evidence, ${ }^{282930}$ however, that furan containing compounds are actively metabolised in the lung to toxic intermediates. With $\mathrm{N}$ amiodarone a similar metabolic mechanism may form the basis of the diffuse alveolar damage.

Most of the patients reported had been given $N$ doses of amiodarone of over $600 \mathrm{mg}$ a day and the $\bar{\sigma}$ pulmonary effects appeared after a variable interval. Difference in susceptibility may result from varia- $\overparen{D}$ tion in the daily dose or the cumulated dose of $\stackrel{\mathscr{C}}{\rightarrow}$ amiodarone and it could be influenced by variation in the ability of individuals to metabolise the drug to reactive intermediates.

The beneficial effects of corticosteroid treatment, $\overparen{\Phi}$ as seen in patient 2 and patient 3 , are obvious but 
difficult to explain. Treatment may diminish the inflammatory processes that are secondary to toxic alveolar damage ${ }^{31}$ It has been suggested ${ }^{16}$ that low dose corticosteroid treatment should be used as prophylaxis against amiodarone pneumonitis. We believe, however, that some caution is called for, especially since the exact nature of the pulmonary changes is as yet unknown. Moreover, Dake and Golden $^{23}$ reported a case in which pulmonary toxicity occurred during amiodarone treatment despite the fact that the patient had been receiving corticosteroid treatment for four years. The pulmonary adverse effects of amiodarone are serious complications with a high mortality rate and, especially in the presence of overt left sided heart failure, the differential diagnosis can be extremely difficult. The attending physician should therefore keep the possibility of amiodarone pneumonitis in mind whenever the drug is being given and, where doubt exists, further diagnostic investigations should be performed, including pulmonary function testing and where possible gallium 67 scintigraphy.

We would like to thank Drs MCP Braat and H Barrowclough for their help and Mrs S Teengs for the drawings, and also $\mathrm{Mr} \mathrm{CM}$ van Hunnik for the photographic reproductions.

\section{References}

1 Vastesaeger M, Gillot P, Rasson G. Etude clinique d'une nouvelle médication anti-angoreuse. Acta Cardiol (Brux) 1967;22:483-500.

${ }^{2}$ Rosenbaum MB, Chiale PA, Halpern MS, et al. Clinical efficacy of amiodarone as an antiarrhythmic agent. Am J Cardiol 1976;38:934-44.

${ }^{3}$ Rosenbaum MB, Chiale PA, Ryba D, Elizari MV. Control of tachyarrhythmias associated with WolffParkinson-White syndrome by amiodarone hydrochloride. Am J Cardiol 1974;34:215-23.

${ }^{4}$ Wellens HJJ, Lie KI, Bär FW, et al. Effect of amiodarone in the Wolff-Parkinson-White syndrome. Am J Cardiol 1976;38:189-94.

${ }^{5}$ Ingram DV. Ocular changes during oral amiodarone treatment. In: Royal Society of Medicine International Congress and Symposium Series, 16. Amiodarone and cardiac arrhythmias. London: Academic Press, 1978:56-61.

- Vos AK, van Ramshorst AGS, Grosfeld JCM, Goossens JP. A peculiar cutaneous pigmentation from cordarone. Dermatologica 1972;145:297-303.

7 Jonckheer MH, Blockx P, Kaivers P, Wijffels G. Hyperthyroidism as a possible complication of the treatment of ischaemic heart disease with amiodarone. Acta Cardiol (Brux) 1973;28:192-200.

${ }^{8}$ Burger $A$, Dinichert $D$, Nicod $P$, Jenny $M$, Lemarchaud-Bérand T, Valloton MB. Effect of amiodarone on serum triiodothyronine, reverse triiodothyronine, thyroxin and thyrotropine: a drug influencing peripheral metabolism of thyroid hormones. J Clin Invest 1976;58:255-9.

${ }^{9}$ Rotmensch HH, Livon M, Tupilski M, Laniado S. Possible association of pneumonitis with amiodarone therapy. Am Heart J 1980;100:412-3.

${ }^{10}$ Heger JJ, Prystowsky E, Jackman WM, et al. Amiodarone: clinical efficacy and electrophysiology during long term therapy for recurrent ventricular tachycardia or ventricular fibrillation. $N$ Engl J Med 1981;305:539-45.

1 Riley SA, Williams SE, Cooke NH. Alveolitis after treatment with amiodarone. Br Med J 1982;284: 161-2.

12 Sobol SM, Rakita L. Pneumonitis and pulmonary fibrosis associated with amiodarone treatment: a possible complication of a new antiarrhythmic drug. Circulation 1982;65:819-24.

${ }^{13}$ Wright AJ, Brackenbridge RG. Pulmonary infiltration and bone marrow depression complicating treatment with amiodarone. $\mathrm{Br}$ Med J 1982;284:1303.

14 Waxman HL, Groh WC, Marchlinski FE, et al. Amiodarone for control of sustained ventricular arrhythmia: clinical and electrophysiologic effects in 51 patients. Am J Cardiol 1982;50:1066-74.

${ }^{15}$ Marchlinski FE, Gansler TS, Waxman HL, Josephson ME. Amiodarone pulmonary toxicity. Ann Intern Med 1982;97:839-45.

${ }^{16}$ Zaher C, Hamer A, Peter T, Mandel W. Low dose steroid therapy for prophylaxis of amiodarone induced pulmonary infiltrates. $N$ Engl $J$ Med 1983;308:779.

${ }^{17}$ Suarez LD, Poderoso JJ, Elsner B, Bunster AM, Esteva H, Bellotti M. Subacute pneumopathy during amiodarone therapy. Chest 1983;83:566-8.

${ }^{18}$ van Zandwijk N, Darmanata JI, Düren DR, Alberts C, Durrer D, Wagenvoort CA. Amiodarone pneumonitis. Eur J Respir Dis 1983;64:313-7.

${ }^{19}$ Morera J, Vidal R, Morell F, Ruiz J, Bernado LI, Laporte JR. Amiodarone and pulmonary fibrosis. Eur J Clin Pharmacol 1983;24:591-3.

${ }^{20}$ Chebat J, Caubarrère I. Pneumopathie grave et amiodarone. Therapie 1983;38:111-2.

${ }^{21}$ Jirik FR, Henning H, Huckell VF, Ostrow DVN. Diffuse alveolar damage syndrome associated with amiodarone therapy. Can Med Assoc J 1983;128:1192-5.

${ }^{22}$ Gefter WB, Epstein DM, Pietra GG, Miller WT. Lung disease caused by amiodarone, a new antiarrhythmic agent. Radiology 1983;147:339-44.

${ }^{23}$ Dake MD, Golden JA. Amiodarone and pulmonary effects. Ann Intern Med 1983;98:1028.

${ }^{24}$ Fogoros FN, Anderson KP, Winkle RA, Swerdlow CD, Mason JW. Amiodarone: clinical efficacy and toxicity in 96 patients with recurrent, drug refractory arrhythmias. Circulation 1983;68:88-94.

${ }^{25}$ Plomp TA, Engels M, Robles de Medina EO, Maes RAA. Simultaneous determination of amiodarone in plasma, urine and tissues by high-performance liquid chromatography. J Chromatogr 1983;273:379-92.

${ }^{26}$ Alberts C, van der Schoot JB, Groen AS. 67 Ga scintigraphy as an index of disease activity in pulmonary sarcoidosis. Eur J Nucl Med 1981;6:205-6.

${ }^{27}$ Katzenstein AA, Askin FB. In: Surgical pathology of non-neoplastic lung disease. Philadelphia: WB Saunders, 1982:9-42. 
${ }^{28}$ Boyd MR, Statham CN, Franklin RB, Mitchell JR. Pulmonary bronchiolar alkylation and necrosis by 3-methylfuran, a naturally occurring potential atmospheric contaminant. Nature 1978;272:270-1.

${ }^{29}$ Reid WD, Ilett KF, Glick JM, Krishna G. Metabolism and binding of aromatic hydrocarbons in the lung. Relationship to experimental bronchiolar necrosis. Am Rev Respir Dis 1973;107:539-51.

${ }^{30}$ Boyd MR, Burka LT. In vivo studies on the relationship between target organ alkylation and the pulmonary toxicity of a chemically reactive metabolite of 4-ipomeanol. J Pharmacol Exp Ther 1978;208:68797.

${ }^{31}$ Wilson JW. Cellular localization of ${ }^{3} \mathrm{H}$-labeled corticosteroids by electron microscopic autoradiography after hemorrhagic shock. In: Glenn TM, ed. Corticosteroids in the therapy of circulatory shock. Baltimore; University Park Press 1974:275-97. 